European Commission

\title{
The spatial profile of university-business research partnerships
}

Pablo D’Este* and Simona lammarino**

* INGENIO and Science and Technology Policy Research (SPRU), University of Sussex

**SPRU, University of Sussex

April 09

IAREG Working Paper 1.3.a

The research leading to these results has received funding from the European Community's Seventh Framework Programme (FP7/ 2007-2013) under grant agreement $n^{\circ} 216813$ 


\title{
The spatial profile \\ of university-business research partnerships
}

\author{
Pable D'Este * Simona Iammarino** \\ *INGENIO, Science and Technology Policy Research (SPRU), University of Sussex \\ **Science and Technology Policy Research (SPRU), University of Sussex
}

\begin{abstract}
University-industry linkages have long been at the centre of academic and policy attention. In spite of the copious literature on different aspects of such linkages, there is still rather inconclusive evidence on both the specific nature of the interactions between universities and businesses and their regional/spatial dimension. This paper focuses on one particular type of linkage between university and business - joint research partnerships - and addresses two specific issues. Firstly, it investigates the extent to which research quality and geographical proximity bear an influence on the intensity of university-industry collaborations. Secondly, it explores the factors affecting the spatial profile (i.e. proximity versus distance) of university-business partnerships. On the basis of an original database on collaborative research grants awarded by the UK Engineering and Physical Sciences Research Council (EPSRC) - integrated with other information sources - our findings generally support previous results highlighting the importance of geographical proximity in shaping university-industry collaborations. Yet, they indicate clearly that the spatial configuration of university-industry linkages is far from being a simple and uniform phenomenon, calling for greater caution when trying to apply "onesize-fits-all" and "picking winners" policy strategies.
\end{abstract}

\section{JEL Classification: 031, O32, 033}

Keywords: university-industry linkages, geographical proximity, collaborative research partnerships 


\section{Introduction}

The role of geographical proximity in shaping the relationship between businesses' innovative activities and university research has been a strong focus of studies on spatially mediated R\&D spillovers. A substantial body of literature has found evidence of the existence of geographically bounded spillovers from university research to industrial innovation (e.g. Jaffe, 1989; Acs et al., 1994; Mansfield and Lee, 1996; Anselin et al., 1997; Henderson et al., 1998; Fritsch and Schwirten, 1999; Arundel and Geuna, 2004; Abramovsky et al., 2007; Fritsch and Slavtchev, 2007; Laursen et al., 2008). However, several issues still remain insufficiently explored and further evidence is needed on the specific nature of the ties that channel knowledge between universities and businesses and on the factors underlying the spatial profile of such ties.

In this study we focus on one particular type of linkage between university and business: research partnerships (or collaborative research projects). Joint research collaborations are particularly important when examining university-business knowledge flows for both policy and conceptual reasons. With regards to the former, the encouragement of university-industry partnerships has been one of the policy instruments most frequently used by national and regional governments to stimulate knowledge transfer between pre-competitive research and industrial innovation (e.g.; Hall et al., 2000; Cohen et al., 2002; OECD, 2002). With regards to the latter, the literature on knowledge spillovers has remained rather vague about the specific mechanisms channelling knowledge. Research partnerships can be indicative of close ties between university and industry that may eventually facilitate localised knowledge spillovers by contributing to the establishment of networks of personal and informal interactions. So far, however, the literature on university-industry linkages has been rather inconclusive about the spatial features of joint research partnerships.

By looking in detail at joint research collaborations between university and business, this paper addresses two specific issues. Firstly, we examine the extent to which research quality and geographical proximity affect the intensity of university-industry research collaborations - where the intensity is measured by the frequency of business partnerships with a certain university department for the purpose of conducting joint 
research. Secondly, we examine the factors that influence the spatial profile of joint research collaborations, paying particular attention to the role of academic research quality.

The paper is organised into six sections. The following Section 2 summarises the literature background. Section 3 provides an in depth explanation of the database and of the variable definitions used in the empirical analysis, whilst section 4 gives a first descriptive analysis of the central issues investigated in the paper. Section 5 contains the econometric analysis and the presentation of the results obtained, whilst section 6 concludes with a discussion of the findings and future research directions.

\section{Literature background}

The literature on the interactions between university and industry has devoted a great deal of attention to geographical proximity. The argument commonly held is that universities located nearby companies are more likely to be perceived as important for the innovation activities of local firms. Particularly advanced or radical innovations draw on new scientific discoveries generated in universities: the exchange of this kind of knowledge requires intense personal interactions, favouring local and regional levels over others (Tödtling et al., 2006, 2009). Thus, geographical proximity to universities provides per se a substantial advantage for firms willing to keep abreast of scientific developments, facilitating and spurring personnel interaction and exchange, and faceto-face contacts (e.g. Jaffe, 1989; Feldman, 1994; Henderson et al., 1998; Mansfield, 1995; Anselin et al., 1997; Fritsch and Schwirten, 1999; Cooke, 2001, 2002; Arundel and Geuna, 2004; Fritsch and Slavtchev, 2007).

On the other hand, as highlighted in the seminal articles of Mansfield $(1991,1995)$ and Mansfield and Lee (1996), academic research quality is another critical factor in moulding the expectations of firms with regard to the university contribution to business research and innovative activities. Academic research excellence is expected to be a strong catalyst for industrial labs that are interested in carrying out joint research activities, attracting in particular those companies that face cutting-edge technology 
issues. As Mansfield and Lee (1996) find out, the universities that are most frequently cited by companies as important contributors to their innovation activities are world leading universities in science and technology. Similarly, Tornquist and Kallsen (1994) show that higher research quality institutions are more likely to produce research susceptible of industry application.

On the joint importance of research quality and geographical proximity in universityindustry collaboration, however, the results of the empirical literature have remained rather inconclusive. On the one hand, Mansfield and Lee (1996) have argued that top ranked universities are more likely to attract businesses located nearby, as compared to lower ranked universities. It has to be noted that Mansfield and Lee (1996) refer to the amount of firms' investment in academic research, leaving the particular nature of the relationship unspecified, i.e. whether it is a joint research project, a targeted-contract research or a consultancy. The argument behind a strong association between top ranked universities and proximity of industry partners lies always on the essential requirement of face-to-face interaction in order to effectively satisfy industrial demands (see also Laursen et al., 2008). One can claim that, if this argument holds for short-term, targeted contracts or consultancy agreements - where the university-business interaction can be often easily managed at arm's length - the same argument should hold even more in the case of joint research partnerships. In fact, joint research partnerships often involve exploratory research and require a great deal of face-to-face interaction among the participants in order to solve the problems derived from the intrinsic complexity and uncertainty of the experimental processes. In these circumstances, geographical proximity among research partners may facilitate the identification of solutions to challenges emerging from the exploratory nature of frontier-science collaborative research.

To sum up, this line of argument would support the contention that top ranked university departments are more likely to interact with spatially close industry partners, since geographical proximity is particularly favourable for leading-edge collaborative research projects. 
On the other hand, other scholars have claimed that top ranked university departments are more likely to attract distant industry partners, as compared to university departments that are low-ranked in terms of research quality (e.g. Adams, 2005). This argument maintains that businesses interested in supporting frontier research at universities are likely to look widely for the best suited university partners, regardless of location. The reason behind is that the more exploratory and cutting-edge the research is, the narrower the choices for university partners in the proximity of a particular firm. In other words, those university departments that conduct frontier research in particular fields of science are likely to attract businesses seeking for unique research skills and academic excellence, and are, therefore, less constrained by geographical distance. As Adams (2005) points out, industry labs that work with top research universities search over longer distances, diminishing the relevance of geographic localisation of academic spillovers.

The empirical findings on such issues have been mixed also with respect to other variables considered in the analysis. For instance, whilst Mansfield and Lee (1996) argue that, other things being equal, firms prefer to work with local university researchers and with more distinguished university departments, they stress that the impact of academic quality and geographical proximity is not homogeneous across disciplinary fields. Their results indicate that the effect of geographical proximity is more pronounced for applied than for basic research, while it is particularly industry conducting basic research which dominantly collaborates with high quality departments (Mansfield and Lee, 1996). Other contributions find marked differences by industrial sector in terms of co-location of R\&D labs and university departments (e.g. Jaffe, 1989; Mansfield, 1995; Abramovsky et al., 2007; Laursen et al., 2008). For example, Abramovsky et al. (2007) show that in industries such as Pharmaceuticals and Chemicals firms locate their R\&D labs in places where there is high concentration of top ranked departments in the relevant fields of research; whilst for other industrial sectors, such as Motor vehicles, the location of R\&D labs is as likely in regions with high concentration of top ranked departments as in regions with high concentration of low ranked departments. 
Furthermore, factors other than research quality and geographical proximity may influence the relevance of a particular university department for industrial innovation activities. For instance, Mansfield (1995) and Tornquist and Kallsen (1994) consider the scale of a university's R\&D activities in the relevant area (i.e. specific faculties), since "a critical mass of researchers and equipment is often regarded as necessary to achieve high productivity in particular aspects of academic research" (Mansfield, 1995: $57)$.

Overall, the existing empirical literature on university-industry interaction and geography has shown a number of limitations. Firstly, as also mentioned above, most of the literature in this field has been conducted by paying scarce attention to the specific "transfer" mechanism of knowledge flows between university and businesses.

Secondly, and relatedly, the bulk of current research has focused on spatial co-location of business and university, rather than on actual interactions. While co-location of university and business units is helpful to assess the extent to which local knowledge spillovers are likely to be present, it is subject to concerns about whether co-location is driven by factors other than the presence of a relevant university department. Moreover, it leaves untouched the question about the precise mechanisms for knowledge transmission: some of the channels for knowledge flows may involve market-related exchanges that are quite remote from pure knowledge spillovers (Breschi and Lissoni, 2001).

Thirdly, a large proportion of the studies attempting to capture the mechanisms of localised knowledge transmission (e.g. mobility of research personnel, patent citations) has mainly focused on university-industry links within highly R\&D intensive industries, particularly biotechnology (e.g. Bania et al., 1993; Zucker et al., 1998; Fabrizio, 2006), failing to provide systematic evidence with respect to a wider range of business sectors.

Fourthly, most studies in this field measure proximity by relying on data taken from administrative boundaries or from somewhat 'arbitrary' measures. For instance, Anselin et al. (1997) measures co-location by considering whether university research is carried out in counties within a given distance band (i.e. either 50 or 75 miles) from the 
location of industry R\&D; Mansfield (1995) measures proximity by the proportion of firms in the sample located in the same state as a given university; Mansfield and Lee (1996), as a proxy for geographical distance, compare universities located less than 100 miles away from the firm with universities located at 100 miles or beyond. These measures clearly provide too broad a definition of spatial proximity.

This paper attempts to overcome these limitations by considering a large sample of university-industry pre-competitive collaborative projects (research partnerships), for which information about the identity and the structural features of both the university departments and the business units involved in the partnerships is available, as well as the precise geographical location of each partner. This allows us to investigate the extent to which certain attributes of the partners, and of the partnerships themselves, bear an influence on the spatial profile of those research partnerships; that is, the factors that affect whether partners are spatially close or distant. Among these factors, in the light of the discussion above, the role of academic research quality deserves special attention.

\section{Data and definitions}

This paper is based on the records of collaborative research grants awarded by the UK Engineering and Physical Sciences Research Council (EPSRC) over the period 19992003. The EPSRC is one of the UK research councils responsible for administering funding for research in the UK. It distributes more than $20 \%$ of the total UK science budget, being the largest council in terms of the volume of research funded.

The EPSRC is responsible for funding research in the areas of engineering and physical sciences, including chemistry, mathematics, computer science and all the engineering fields, which represent the bulk of the EPSRC funding. While the EPSRC also welcomes research proposals that span the remits of other research councils (such as research projects in biology, social science, or medical-related research) this paper restricts the analysis to collaborative grants within the main remits of the Council. 
The EPSRC encourages partnerships between university researchers and the potential users and beneficiaries of research. ${ }^{2}$ Our focus here is specifically on EPSRC grants that involve business companies as collaborative partners. In this type of grants university researchers collaborate with businesses in the course of the research project, and businesses may provide either funds or in-kind support (or a combination of both) to the joint project. We will refer to these collaborative research projects as universityindustry partnerships, and they represent our main unit of analysis.

\subsection{Main features of the university-industry partnerships dataset}

Our set of university-industry partnerships consists of all the collaborative grants with businesses awarded by the EPSRC over the period 1999-2003. This dataset covers 2210 research grants involving 4525 distinct partnerships between universities and businesses (there may be more than one business taking part in a research grant). 2031 different business units ${ }^{3}$ are involved in these partnerships, together with 1566 principal investigators affiliated to 318 different university departments (covering $87 \mathrm{UK}$ universities).

As Table 1 shows, the larger proportion of our 4525 partnerships corresponds to the broad field of engineering, with Mechanical, Electrical and General Engineering accounting for almost $50 \%$ of the partnerships. Overall, $75 \%$ of the partnerships could be classified as engineering-related, while $25 \%$ as basic-science related (i.e. those partnerships in the disciplines of chemistry, computer science, mathematics and physics).

[Table 1 about here]

Table 2 displays the breakdown of the partnerships according to the industry of the business units involved. Over $40 \%$ of the partnerships engage business units in the

\footnotetext{
${ }^{2}$ Partners may include those working in industry, commerce, government agencies, local authorities, public bodies, National Health Service (NHS) Trusts, non-profit organizations, research and technology organizations or the service sector. As a result, almost $45 \%$ of EPSRC funded research grants involve collaboration with industry partners.

${ }^{3}$ Business units refer to a dyad 'company name' - 'specific location'. This means that multiple locations of a single corporation are treated here as different business units.
} 
service sector, including Computer Services (5\%), R\&D (5\%) and Consultancy and other Business Services (17\%). For manufacturing industries, Chemicals \& Chemical Related (12\%), Machinery and Metals (10\%) and Electrical \& Electronics (9\%) are the industries most involved in partnerships.

[Table 2 about here]

With respect to the territorial breakdown, partnerships have been attributed to regions according to the university location and to the business location, using the information provided by the postal codes. We have followed the NUTS 1 classification provided by EUROSTAT for the UK regions, while we have considered all the businesses located outside the UK as belonging to a single territorial category - i.e. Outside UK. South East is the region with the largest proportion of partnerships according to the location of industry partners (i.e. $21.8 \%$ ), whilst London is the region with the largest proportion of partnerships according to the location of universities (15.4\%). It is worth noticing that only $5.4 \%$ of the partnerships involve companies located outside the UK, while all universities are located within the UK.

Crucially for our study, we are able to identify precisely which university departments are involved in research partnerships. This allows us to gather information about the quality of the research conducted by the departments involved by matching data from the results of the UK Research Assessment Exercise 2001 (RAE 2001, covering the period 1996-2000). The primary purpose of the RAE is to provide ratings of research quality to be used by the UK higher education funding bodies in determining the main block grants for research, for the institutions they fund. Universities submit the results of their research activity for the assessment of all or some fraction of the research staff in the selected departments, within 68 subject research areas. ${ }^{4}$ Each department submission is rated on a seven-point scale from 1 to $5^{*}$ - with $5^{*}$ being the highest score, indicating that in more than a half of the department's submitted activities research quality has achieved international excellence, and that the remaining activities have reached national excellence. ${ }^{5}$

\footnotetext{
${ }^{4}$ Although submission to the RAE is not mandatory, the incentives for participation are high as public research funding depends on the assessment.

${ }^{5} \mathrm{RAE}$ results and ratings definitions for 2001 are publicly available at
} 
Using the RAE department ratings, we recodified the rating scale into 1 to 7 (raescore) ${ }^{6}$ and constructed three categories: one for top ranked departments, corresponding to those departments ranked as $5^{*}$ (or that have a ranking value of 6.5 or above with the recodification) (toprank); medium-high ranked departments, corresponding to university departments with a RAE score around 5 (or a ranking value between 5.5 and 6.49 with the recodification) (medrank); and low ranked departments, corresponding to university departments with a RAE score of 4 or below (or below 5.5 with the recodification) (lowrank). ${ }^{7}$

As reported in Table 3, of the 4525 partnerships in our dataset about $29 \%$ were with departments ranked in the lower categories; $42 \%$ in the medium category; and $29 \%$ in the top category. This distribution of university departments is significantly different from that corresponding to the whole population of university departments that submitted to the UK RAE 2001 within the fields of physical sciences and engineering. The distribution of the latter was as follows: about $55 \%$ of the departments were ranked 4 or below; about $33 \%$ were ranked 5 ; and $12 \%$ were ranked $5 *$. Therefore, the distribution of department according to research quality rankings in our dataset reflects the fact that university-industry partnerships take place particularly with higher ranked departments.

[Table 3 about here]

\subsection{Spatial profile of the university-industry partnerships dataset}

\footnotetext{
http://www.hero.ac.uk/rae/Pubs/index.htm. E.g. 5 is defined as: "quality that equates to attainable level of international excellence in up to a half of the research activity submitted and to attainable levels of national excellence in virtually all of the reminder". 4 is defined as: "quality that equates to attainable levels of national excellence in virtually all of the research activity submitted, showing some evidence of international excellence". 1 is defined as: "quality that equates to attainable levels of national excellence in none, or virtually none, of the research activity submitted".

${ }^{6}$ Transforming the original scale $1,2,3 \mathrm{~b}, 3 \mathrm{a}, 4,5$ and $5^{*}$, into the corresponding following values: 1,2 , $3,4,5,6$ and 7 .

${ }^{7}$ The reason for decimals in some rankings responds to the fact that some university departments have more than one research unit submitting to the RAE, and in those cases an average of the corresponding scores has been computed.
} 
We also collected information on the geographical distance between university-industry partners across all the partnerships in our dataset. Geographical distance is calculated as the distance expressed in $\mathrm{km}$ between the business unit's location and the university partner's location. The distance between company and university was calculated on the basis of the postcodes of the business unit and the university involved in any particular partnership. ${ }^{8}$

As Table 4 shows, the average and median distances corresponding to our whole set of partnerships are 268 and $148 \mathrm{Km}$, respectively. Also, a quarter of the partnerships in our dataset has a geographical distance lower than $70 \mathrm{~km}$, and another quarter corresponds to distances above $261 \mathrm{Km}$.

[Table 4 about here]

Finally, with regards to the cross-regional profile of the partnerships, it is important to bear in mind that $20 \%$ of the partnerships takes place within the same NUTS 1 region, $35 \%$ occurs between partners located in neighbouring regions, and $45 \%$ takes place between regions that have no common boundaries - i.e. faraway regions. Table 5 shows that both the median and average distances differ substantially between partnerships established within the same UK NUTS 1 region as compared to partnerships that take place between a university and a firm located in different non-neighbouring regions.

[Table 5 about here]

\section{Factors influencing the spatial profile of partnerships: a descriptive analysis}

This section discusses the extent to which geographical distance between partners involved in university-industry partnerships exhibits some systematic features

\footnotetext{
${ }^{8}$ The distances were collected using the GRIDLINK database which links postcodes to grid values. These grid values have a geographical positioning accuracy of within $100 \mathrm{~m}$. The grid values allowed us to estimate the linear distance between two grid points using postcodes. We were thus able to measure the geographic distance between each business unit in the dataset and the universities with which it collaborates. We thank T. Reichstein (CBS) and A. Salter (ICL) for these data and methodology.
} 
according to different attributes of such partnerships. In particular, this section investigates whether there are significant differences in the spatial profile of partnerships according to: a) industry sectors; b) location of industry partners; c) field of science; and d) the research quality of university partners.

\section{Distance of partnerships by industrial sector}

There are some marked differences across sectors in terms of the proportion of partnerships that takes place within a certain distance. The two extremes are represented by Computer Service firms and Transport firms. Partnerships with universities established by companies in Computer Services exhibit the shortest distances, with $25 \%$ of the partnerships within a band of $35 \mathrm{~km}$. Conversely, Transport companies exhibit the longest distances in their partnerships with universities, with more than $75 \%$ of partnerships beyond a distance of $90 \mathrm{~km}$.

All other sectors fall somewhere in between these two extreme cases. To summarise, in addition to Transport, Chemicals \& Chemical Related and R\&D services are above the median distance, whilst Electrical \& Electronics, Instruments, Machinery, Computer Services, Utilities \& Construction and Consultancy Services are below the median distance for the overall sample.

\section{Scientific field}

From the literature briefly discussed in Section 2, we would expect some marked differences in the spatial profile of partnerships across scientific disciplines, and particularly between basic science-related disciplines and engineering-related ones. Indeed, on the basis of our dataset, significant differences emerge both between the two broad groups of disciplines, and among the 10 scientific disciplines considered separately. More specifically, while the median distance for basic-science related partnerships is $178 \mathrm{~km}$, for engineering-related partnerships is around $140 \mathrm{Km}$, and the proportion of partnerships below the overall median $(148 \mathrm{Km})$ is significantly higher for engineering than for basic related disciplines ( $52 \%$ and $45 \%$, respectively).

Also, there are significant differences with respect to the proportion of partnerships below $70 \mathrm{~km}$ - the threshold that cuts off $25 \%$ of partnerships. More precisely, while 
Chemical Engineering, Chemistry and Civil Engineering have less than 22\% of partnerships below $70 \mathrm{~km}$ distance, Electrical \& Electronic Engineering, Physics, Mathematics Mechanical Engineering and Computer Science, have all more than 27\% of partnerships below that threshold. However, on this account, differences are significant between disaggregated discipline categories, but not between basic-science and engineering-related disciplines as two broad categories.

\section{Research quality of university partners}

Since one of the main objectives of this paper is to examine whether the spatial profile of university-industry partnerships is influenced by the research quality of the university partner, this sub-section provides some descriptive information on such an issue. Drawing upon our dataset, we observe significant differences in the spatial profile of partnerships according to the university department quality rank. In particular, partnerships with highly ranked university departments are those that display a lower median distance $(128 \mathrm{~km})$ as compared to those of medium and low ranked departments (165 and $153 \mathrm{~km}$, respectively). As Table 6 shows, the proportion of partnerships below the median for the overall sample is significantly higher for top-ranked departments than for all other department rankings.

\section{[Table 6 about here]}

However, differences are not significant when we look at a tighter measure of geographical proximity: the proportion of partnerships below $70 \mathrm{~km}$ (the first quartile threshold for the distance distribution). In that respect, we do not observe significant differences in the proportion of partnerships below $70 \mathrm{~km}$ according to quality rank of the university department (Table 6). In this case, the record that leaves $25 \%$ of partnerships below a certain distance is $68 \mathrm{Km}$ for low-ranked departments, $73 \mathrm{~km}$ for medium-rank departments and $68 \mathrm{~km}$ for top-ranked departments.

When we examine basic-science and engineering-related fields separately, we observe exactly the same pattern. In both cases, top ranked departments are those with a significantly larger proportion of partnerships below the overall median. Yet, once 
again, differences are not significant across types of departments when we compare the proportion of partnerships below the first-quartile distance threshold.

To sum up, there seems to be significant differences in the spatial profile of partnerships depending on: industrial sector, academic discipline and the quality rank of the university department involved in the partnerships. In particular, it seems that engineering-related disciplines and top-ranked departments are more likely to involve geographically closer partnerships (at least with respect to the median distance of partnerships).

\section{Econometric Analysis}

This section aims at examining the two questions presented in Section 1. First we describe the variables used in the analysis; then, we investigate the extent to which geographical proximity and research quality influence the intensity of universityindustry collaboration (first part of the analysis); finally, we examine the factors that shape the spatial profile of partnerships (second part of the analysis).

\subsection{Description of variables}

For the first part of the analysis, we consider the number of partnerships established by a particular university department as our dependent variable. This variable is intended to measure the extent to which the research conducted in a university department is considered relevant for innovative activities by businesses, thus determining the intensity of collaborations. We therefore assume the university department as unit of analysis (our dataset contains 318 distinct university departments) and consider mainly three explanatory factors: a) geographical proximity of business partners, as measured by the average distance of all partnerships held by a university department with businesses over the five years time frame (avg-distance); b) research quality of the university department, as measured by the score awarded to the department through the UK Research Assessment Exercise (quality_score); c) the volume of income for research received by the department, normalized by the number of researchers in the 
department (income_pc); and d) the size of the university department, as measured by the number of research active staff in the department (dep_size). ${ }^{9}$

For the second part of the study, our dependent variable is the geographical distance (measured in $\mathrm{Km}$, logarithmically transformed) between each university department and the business unit involved in a research partnership. Thus, the partnership is the unit of analysis, allowing us to work with all our sample of individual university-business dyads contained in the original data of EPSRC funded projects (i.e. 4525 records). The main explanatory variables are related to the research quality of the university partner, both at the university and the department levels. In order to study such features we defined a set of dummy variables. First, toprank is a dummy that that takes value 1 if the university department was ranked as a $5^{*}$ department by the UK RAE 2001, and zero otherwise. Second, lowrank is a dummy that takes value 1 if the university department was ranked 4 or below by the UK RAE 2001. Third, res_int_univ is a variable that takes value 1 if a university is among the group of research intensive UK universities - i.e. the so-called Russell Group. Finally, a fourth dummy, expolytechnics, takes the value of 1 if a university is among the ex-polytechnic universities, that is those universities that, since their inception, have had an explicit mission of engagement with the local community and contribution to economic growth.

We have also used a number of control factors. In both parts of the analysis we controlled for a set of dummies accounting for the different disciplines to which the university departments belong (i.e. 9 dummies) and the different regions where the business units are located (i.e. 9 dummies). ${ }^{10}$ In the second part of the analysis, we considered an additional set of control variables. Firstly, the number of universities within the same region where a business unit is located, to account for the fact that a

\footnotetext{
${ }^{9}$ The data for these last three variables at the department level come all from the same source: the records from the RAE 2001. All the variables, therefore, refer to information at the departmental level collected for the period 1996-2000. For the purpose of this paper, we have calculated the average of total funding per active researcher and the average research staff for the five year period 1996-2000. It is worth noting that this five-year period does not totally overlap with the period considered in our dataset on universityindustry partnerships (i.e. 1999-2003). However, bearing in mind that neither research quality, nor size and total funding for research are likely to exhibit dramatic changes in the short run, we believe that these three measures are accurate approximations for an average year with respect to the period 1999-2003.

${ }^{10}$ Our reference category is Mechanical, Aero. \& Manuf. Engineering, in the case of disciplines; and South East in the case of regions, taking into account that Wales, Scotland and Northern Ireland were considered together in a single dummy.
} 
company is more likely to interact with a nearby university if it has a wide range of options locally available (n_univ). ${ }^{11}$ Secondly, the number of partnerships in which a business unit was involved in the period 1999-2003 (logarithmically transformed). This captures the presence of recurrent industry partners (versus sporadic ones), since it is likely that recurrent partners may be less constrained by geographical location in their choice for university partnerships (num_partn). Thirdly, we controlled for the size of the grant, in terms of total funding provided by the UK funding agency (grant_vol, a variable that is also logarithmically transformed). Finally, because in this second stage of the study we can identify the precise business partner involved in the partnership, we also controlled for the different industry sector (i.e. 10 dummies - with Chemistry and Chemical Related as reference category).

\subsection{Geographical proximity, research quality and the intensity of university- business partnerships}

As explained above, our dependent variable is the number of partnerships with businesses of each university department over the period 1999-2003. This variable ranges from a minimum of 1 to a maximum of 145. Descriptive statistics for all variables in the empirical model are presented in Table 1A. in the Appendix.

Since our dependent variable is a non-negative integer showing a highly skewed distribution, both Poisson and Negative Binomial regression models for count data were considered. As there is significant evidence of overdispersion, the negative binomial regression model was preferred. ${ }^{12}$ Also, to take into account that the effect of each explanatory variable may differ between engineering-related disciplines and basicscience related ones, the statistical analysis was carried out for all disciplines as a whole group and for each of the two distinct groups of disciplines separately.

\footnotetext{
${ }^{11}$ Including this variable in the analysis implies that we remove from our dataset those partnerships that involve companies located outside the UK (i.e. 244 observations). To check for the robustness of the estimates, the results are reported also excluding this variable (that is, working with the full dataset of partnerships).

${ }_{12}^{2}$ Our sample of 318 departments covers almost $70 \%$ of university departments that are research active (i.e. submitted to RAE 2001) in the fields of Engineering and Physical Sciences. Therefore, as our dependent variable ranges from 1 to 145 , and we have no observation with zero records, we are virtually covering the large majority of the population of research active departments. The results of the Poisson regression model and of OLS with a logarithmically transformed dependent variable are available from the authors.
} 
As Table 7 shows, results indicate that, when all disciplines are considered together (column I), both distance and research quality have a significant impact on the number of partnerships with industry established by university departments. On the one hand, distance with industry partners is negatively related to the frequency of collaborations, indicating that geographical proximity facilitates research partnerships between university and businesses. On the other hand, the quality rank of the university department is positively and significantly associated with the frequency of partnerships, indicating that university departments that carry out research of higher scientific impact are more likely to attract a larger number of research collaborations with businesses.

\section{[Table 7 about here]}

However, when splitting the university departments according to the two sub-groups of disciplines, we observe substantial differences with respect to the impact of distance and research quality on the intensity of collaborations. Whilst for engineering-related departments proximity matters in explaining the number of collaborations with industry, this is not the case for basic-science related departments, where instead we found a positive impact of research quality (though the coefficient is significant at $10 \%$ only). In all cases, the size of department is strongly correlated with the frequency of collaboration, whilst the amount of research income per researcher is statistically significant only in the case of engineering departments. In addition, it is interesting to note that engineering departments in ex-polytechnic universities attract lower numbers of research collaborations with industry relatively to departments located in other types of universities, while research intensive universities (Russel Group) seem to bear no impact on the number of research collaborations.

\subsection{Factors shaping the spatial profile of university-business partnerships}

This section considers the data at the partnership level, and examines the factors that shape the spatial profile of research collaborations between university and businesses. As noted above, our overall sample consists of 4525 partnerships for the period 1999- 
2003. Descriptive statistics for all variables considered in the study are shown in Table $1 \mathrm{~B}$ in Appendix. ${ }^{13}$

[Table 8 about here]

As the results of the OLS regressions in Table 8 show, the research quality of the university partner influences the spatial profile of the relationship. For the overall sample, we observe that top ranked departments are significantly associated with geographically closer partnerships. That is, research partnerships involving top ranked departments exhibit significantly shorter distances as compared to partnerships involving university departments with a lower research quality ranking (column I). When looking at the other end of the spectrum, we observe that the impact of the bottom ranked departments is the opposite: partnerships involving low ranked departments exhibit significantly larger geographical distances (column II).

It is also interesting to note that, when looking at university features, both research intensive universities and ex-polytechnic universities have partnerships exhibiting significantly shorter distances as compared to partnerships with other type of universities.

However, this profile changes when distinguishing between engineering and basicscience related university departments. Although in both cases partnerships involving top ranked departments exhibit shorter distances, the impact of research excellence on geographical proximity is more significant (5\% level|) for basic-science disciplines than for engineering-related fields. In addition, only in the case of the latter low ranked departments have a significant association with more distant partnerships; on the contrary, for basic-science departments low rank has no significant bearing on the distance between university and industry partners. More precisely, low ranked

\footnotetext{
${ }^{13}$ Note that for the purpose of the statistical analysis here conducted we have not considered the 244 partnerships that involve companies located outside the UK. The main reason for this is that, in order for their inclusion to make sense, we would also need information on partnerships established between our sample of firms located in the UK with non-UK universities. In other terms, to have an appropriate account of distances in the context of research partnerships, we would need the two sides of the internationalisation phenomenon. Since this is not possible on the basis of partnerships founded by a UK Research Council (i.e. which exclude projects were the PI is a non-UK university), we have preferred to concentrate on those partnerships that involve universities and businesses located in the UK which, in any case, represent $95 \%$ of our sample of partnerships.
} 
departments in basic-science disciplines are as likely to attract geographically close industry partners as medium or top ranked departments.

Another substantial difference between engineering and basic departments refers to the influence of the university features. While in the case of engineering departments partnerships involving ex-polytechnic universities exhibit significantly shorter distances, ex-polytechnic universities have no significant impact on the spatial profile of partnerships for basic-science related departments. ${ }^{14}$ Conversely, for the latter, research intensive universities show significantly shorter distances among partners, whilst the spatial profile of partnerships in the case of engineering-related departments is not affected by the involvement of research intensive institutions.

The other control variables have, in general, the expected sign, and they show similar patterns for both basic-science and engineering-related departments. First, the more frequently a business unit interacts with university, the less likely it is that geographical proximity matters (the coefficients are positive and strongly significant in all cases). Secondly, the larger the number of universities located within the same NUTS 1 region of a specific industry partner, the more likely that the collaboration involves geographically close partners. Third, larger departments are more likely to involve industry partners located close to the university. Some differences emerge with regards to the funding features of the university department: whilst for engineering-related fields such features do not have any influence on the spatial patterns of partnerships, in the case of basic sciences departments with higher public funding per researcher are more likely to attract distant industry partners, while departments with larger volume of funding from industry are more likely to attract nearby industry partners (though these results are only weakly significant).

\footnotetext{
${ }^{14}$ It is important to bear in mind that, out of the 1163 partnerships with basic-related departments, only 51 partnerships involve ex-polytechnic universities.
} 


\section{Conclusions}

This paper has tried to overcome some of the limitations of the previous literature on university-business linkages in a spatial perspective. In particular, we have focussed on a specific type of interaction, that is research partnerships between university and industry; we have employed an actual definition of spatial proximity; we have covered a rather wide range of industrial sectors of the firms involved in research collaborations with university partners.

Our results first of all confirm the main findings of the previous literature: both geographical proximity and research quality have a significantly positive impact on the intensity of university-industry partnerships, generally shoring up the spatially bounded nature of knowledge spillovers. However, in line with Mansfield and Lee (1996), results are not homogenous when considering different scientific disciplines. Whilst for engineering-related departments proximity is highly relevant in explaining the intensity of collaborations with industry, this is not the case for basic-science related departments, where instead a positive impact of research quality prevails (not significant for engineering-related scientific fields).

As for the geographical profile of research partnerships, we found strong support for the argument of a higher likelihood of top ranked universities to interact with geographically close partners. Conversely, low ranked university research has a higher probability to involve distant partners only in the case of engineering-related disciplines, bearing no impact on the geography of basic-science fields of research.

Furthermore, the present paper has provided interesting results on other structural and systemic features of the spatial profile of university-industry interactions, supporting at least indirectly - the relevance of the regional location (i.e. the higher the "critical mass' in terms of university presence and size in a region, the higher the likelihood of localised spillovers); the importance of adaptive learning processes to develop interactive capabilities at the firm level (i.e. the more frequent are collaborations with universities, the more likely is to engage in extra-regional collaborations); the different responsiveness of scientific areas (high for basic-science, null for engineering-related 
disciplines) to public funding (seemingly spurring more long-distance collaborations) or private funding (attracting more local business partners).

All this suggests that the spatial configuration of university-industry linkages is far from being a simple and uniform phenomenon. A complex set of overlapping factors - most of them embedded in the industrial and scientific structure of regional systems underlie the relevance of geographical proximity and the actual potential for localised knowledge spillovers (see also Salter and Martin, 2001; Laursen and Salter, 2004; Laursen et al., 2008). This calls for greater caution when trying to devise public policy implications and tools for encouraging university-industry linkages, avoiding, on the one hand, the "one-size-fits-all" model, which may not take into account key features of the context in which collaborations occur (or not); and, on the other, also preventing from an excessive concentration of government funds according to "picking winners" strategies in search of regional/national business and academic champions (see also Cooke, 2009).

Our study has also a number of limitations, among which the constraints in the analysis of research partnerships involving internationally located industry partners; and the lack of a region-specific analysis that would allow for a better grasping of spatial and systemic features of such partnerships and of the role of geography in generating knowledge spillovers. We consider this paper as a first step in these directions. 


\section{References}

Abramovsky L., Harrison R. and Simpson H. (2007), "University research and the location of business R\&D”, Economic Journal 117 (519): 114-141.

Acs Z., Audretsch D. and Feldman M. (1994), "R\&D spillovers and recipient firm size", The Review of Economics and Statistics 76: 336-340.

Adams J.D. (2005), "Comparative localization of academic and industrial spillovers". In Breschi S. and Malerba F. (eds.) Clusters, networks and innovation, Oxford University Press, Oxford.

Anselin L., Varga A. and Acs Z. (1997), "Local geographic spillovers between university research and high technology innovations", Journal of Urban Economics 42: 422-448.

Anselin L., Varga A. and Acs Z. (2000), "Geographic and sectoral characteristics of academic knowledge externalities", Papers in Regional Science 79: 435-443.

Arundel A. and A. Geuna (2004), "Proximity and the use of public science by innovative European firms", Economics of Innovation and New Technologies 13, 559580.

Audretsch D., Lehmann E.E. and Warning S. (2005), "University spillovers and new firm location", Research Policy 34: 1113-1122.

Bania N., Eberts R.W. and Fogarty M.S. (1993), "Universities and the startup of new companies: can we generalize from Route 128 and Silicon Valley", The Review of Economics and Statistics 75 (4): 761-766.

Breschi S. and F. Lissoni (2001), "Knowledge spillovers and local innovation systems: a critical survey", Industrial and Corporate Change 10, 975-1005.

Cohen W.M., Nelson R.R. and Walsh J. (2002), "Links and Impacts: The Influence of Public Research on Industrial R\&D”, Management Science 48, 1-23.

Cooke P. (2001), "Regional Innovation Systems, Clusters, and the Knowledge Economy", Industrial and Corporate Change 10, 945-974.

Cooke P. (2002), Knowledge Economies. Clusters, Learning and Cooperative Advantage, London: Routledge.

Cooke P. (2009), "Economic development policy as an evolutionary envisioning process", in: Regional Innovation Policy: What, Where and Why?, OECD, Paris, forthcoming.

Fabrizio K. (2006), The use of university research in firm innovation, in: $\mathrm{H}$. Chesbrough, W. Vanhaverbeke, and J. West (eds), Open Innovation; researching a new paradigm, Oxford University Press, London.

Feldman M.P. (1994), The Geography of Innovation, Kluwer Academic Press, Amsterdam.

Fritsch M. and Schwirten C. (1999), "Enterprise-university co-operation and the role of public research institutions in regional innovation systems", Industry and Innovation, 6, 69-83. 
Fritsch M. and Slavtchev V. (2007), "Universities and innovation in space, Industry and Innovation", 14, 201-218.

Hall B.H., Link A.N. and Scott J.T. (2000), "Universities as research partners", NBER Working Paper No. 7643.

Henderson, R., A. Jaffe and M. Trajtenberg (1998), "Universities as a source of commercial technology: a detailed analysis of university patenting, 1965-1988", The Review of Economics and Statistics LXXX, 119-127.

Jaffe, A.B. (1989), "Real effects of academic research", The American Economic Review 79 (5): 957-970.

Laursen K. and Salter A. (2004), "Searching low and high: what types of firms use universities as a source of innovation?”, Research Policy 33, 1201-1215.

Laursen K., Reichstein T. and Salter A. (2008), "Exploring the effect of geographical proximity on industry-university collaboration in the UK". Paper presented at the DRUID $25^{\text {th }}$ Celebration Conference 2008, Denmark, June 17-20.

Mansfield E. (1991), "Academic research and industrial innovation”, Research Policy 20: $1-12$.

Mansfield E. (1995), “Academic research underlying industrial innovations: sources, characteristics, and financing", The Review of Economics and Statistics 77: 55-65.

Mansfield E. and Lee J-Y. (1996), "The modern university: contributor to industrial innovation and recipient of industrial R\&D support" Research Policy 25 (7): 10471058 .

Muscio A. (2009), "University-industry linkages: what are the determinants of longdistance collaborations" (manuscript provided by the author)

OECD (2002), Benchmarking industry-science relationships. Paris: OECD.

Salter A. and Martin B.R., "The economic benefits of publicly funded basic research: a critical review", Research Policy 30: 509-532.

Tödtling, F., Lehner, P. and Kaufmann, A. (2009), "Do Different Types of Innovation Rely on Specific Kinds of Knowledge Interactions?", Technovation, forthcoming.

Tödtling, F., Lehner, P. and Trippl, M. (2006), "Innovation in Knowledge Intensive Industries: The Nature and Geography of Knowledge Links", European Planning Studies, 14, 8, 1035-1058.

Tornquist K.M. and Kallsen L.A. (1994), "Out of the ivory tower: characteristics of institutions meeting the research needs of industry", The Journal of Higher Education 65 (5): 523-539.

Zucker L., Darby M.R. and Brewer M.B. (1998), "Intellectual human capital and the birth of US biotechnology enterprises", The American Economic Review 88 (1): 290306. 
Table 1. University-industry partnerships: breakdown by scientific discipline

\begin{tabular}{lc}
\multicolumn{1}{c}{ Discipline } & \% of partnerships \\
\hline Chemical Engineering & 6.0 \\
Chemistry & 9.4 \\
Civil Engineering & 11.0 \\
Computer Science & 7.4 \\
Electrical and Electronic Engineering & 14.5 \\
General Engineering & 11.6 \\
Mathematics & 2.5 \\
Mechanical, Aero. and Manufacture Eng. & 21.3 \\
Metallurgy and Materials & 9.9 \\
Physics & 6.3 \\
Total (\%) & $100 \%$ \\
Number & 4525 \\
\hline
\end{tabular}


Table 2. University-industry partnerships: breakdown by industry

\begin{tabular}{lc}
\hline \multicolumn{1}{c}{ Industry } & \% of partnerships* \\
\hline Chemicals \& Chemical Related & 11.8 \\
Electrical \& Electronics & 9.3 \\
Instruments & 5.9 \\
Machinery \& Metals & 10.4 \\
Transport & 7.7 \\
Utilities \& Construction & 8.0 \\
Manufacture n.e.c. & 3.9 \\
Computer Services & 5.1 \\
Research \& Development & 5.4 \\
Consultancy and other Business Services & 17.4 \\
Services n.e.c. & 15.3 \\
Total (\%) & $100 \%$ \\
Number & $4142^{* *}$ \\
\hline
\end{tabular}

* Percentage of partnerships involving a company from one of the 11 industries considered.

** It is important to note that for some of the business units it was not possible to identify an unambiguous ISIC code. This was the case for business units involved in 383 partnerships.

\footnotetext{
- Chemicals \& Chemical Related include firms in sectors such as Manufacture of chemicals and chemical products, Manufacture of rubber and plastic products and Manufacture of other non-metallic mineral products (ISIC codes 24 to 26). Electrical/Electronics include: Manufacture of electrical and optical equipment, manufacture of electrical machinery, and manufacture of radio, TV and communication equipment (ISIC 30-32). Instruments include Manufacture of medical, precision and optical instruments (ISIC 33). Machinery/Metals include Manufacture of basic metals and fabricated metal products and Manufacture of machinery and equipment (ISIC 27-29). Transport includes Manufacture of transport equipment (ISIC 34-35). Utilities \& Construction include Electricity, gas and water supply and Construction (ISIC 40-41 and 45). Manufacture not elsewhere classified includes Mining and Quarrying, Manufacture of food products, beverages and tobacco, Manufacture of textile products, Manufacture of wood products, among others. Computer Services include Computer and related activities (ISIC 72) (including Hardware and Software consultancy and maintenance and repair of office computing machinery, among others). Research \& Development includes Research and Development (ISIC 73). Other Business Services include Other business activities (ISIC 74) (including engineering and technical consultancy, technical testing and analysis and accounting among others). Services n.e.c. include Wholesale and Retail trade, Hotels and Restaurants, Financial intermediation, etc.
} 
Table 3. Distribution of partnerships by department rank

Department rank

$\%$ of Partnerships

(Total number of partnerships, 4521)*

Below or equal to a RAE score of 4

$29.1 \%$

Equal to a RAE score of 5

$41.7 \%$

Equal to a RAE score of $5^{*}$

$29.2 \%$

*Note: there are 4 cases for which a match between names of university and department and the corresponding RAE score could not be found.

Table 4. Geographical distance: descriptive statistics

\begin{tabular}{cccccc}
\hline $\begin{array}{c}\text { Mean } \\
(\mathrm{km})\end{array}$ & $\begin{array}{c}\text { Median } \\
(\mathrm{km})\end{array}$ & $\begin{array}{c}\text { Minimum } \\
(\mathrm{km})\end{array}$ & $\begin{array}{c}\text { Maximum } \\
(\mathrm{km})\end{array}$ & $\begin{array}{c}1 \mathrm{st} \\
\text { Quartile }\end{array}$ & $\begin{array}{c}3^{\text {rd }} \\
\text { Quartile }\end{array}$ \\
\hline 268.3 & 148.2 & 0 & $2000.0^{*}$ & 69.6 & 260.6 \\
\hline
\end{tabular}

* Distances for business units located Outside UK are truncated at $2000 \mathrm{Km}$.

Note: There are 133 cases for which distances could not be computed mainly as a consequence of wrong postcodes (i.e. not recognised as valid ones). Therefore, the figures in Table 4 refer to 4392 partnerships.

Table 5. Average distance by spatial profile of partnerships

\begin{tabular}{lcc}
\hline \multicolumn{1}{c}{ Region } & Average distance & Median distance \\
\hline Within region & $36 \mathrm{Km}$ & $21 \mathrm{Km}$ \\
Between neighbouring regions & $114 \mathrm{Km}$ & $105 \mathrm{Km}$ \\
Between faraway regions & $484 \mathrm{Km}$ & $266 \mathrm{Km}$ \\
Total & $268 \mathrm{Km}$ & $148 \mathrm{~km}$ \\
\hline
\end{tabular}

Table 6. Proportion of partnerships by quality ranked departments

\begin{tabular}{lcc}
\hline Quality ranked Departments & $\begin{array}{c}\text { \% of partnerships below } \\
\text { first quartile }\end{array}$ & $\begin{array}{c}\text { \% of partnerships } \\
\text { below median }\end{array}$ \\
\hline Highly ranked departments & 26.0 & 56.2 \\
Medium ranked departments & 24.1 & 46.6 \\
Low ranked departments & 25.3 & 48.4 \\
Chi-squared Test (prob.) & Not sign. $(p>0.1)$ & Significant $(p<0.001)$ \\
\hline
\end{tabular}


Table 7. Negative Binomial estimates. Dependent variable: number of research collaborations with businesses by university departments

\begin{tabular}{lccc}
\hline & $\begin{array}{c}\text { All Disciplines } \\
(\mathrm{I})\end{array}$ & $\begin{array}{c}\text { Engineering related } \\
(\mathrm{II})\end{array}$ & $\begin{array}{c}\text { Basic-science related } \\
(\mathrm{III})\end{array}$ \\
\hline Average distance $(\mathrm{km})$ & $-0.0004 * * *$ & $-0.0009 * * *$ & -0.0002 \\
& $(0.0001)$ & $(0.0002)$ & $(0.0001)$ \\
Research quality score & $0.170 * * *$ & 0.123 & $0.161 *$ \\
& $(0.066)$ & $(0.079)$ & $-0.085)$ \\
Total research income p.r. & 0.003 & $0.016 * * *$ & $(0.002)$ \\
& $(0.002)$ & $(0.003)$ & $0.012 * * *$ \\
Department size & $0.016 * * *$ & $0.023 * * *$ & $(0.005)$ \\
& $(0.003)$ & $(0.003)$ & -0.161 \\
Res. Intensive Univ. & -0.152 & -0.172 & $(0.153)$ \\
& $(0.101)$ & $(0.128)$ & -0.313 \\
Ex-polytechnic Univ. & $-0.492 * * *$ & $-0.412 *$ & $(0.254)$ \\
& $(0.187)$ & $(0.234)$ & $0.848 *$ \\
Intercept. & 0.217 & $0.918 *$ & $(0.446)$ \\
& $(0.354)$ & $(0.496)$ & Included \\
Disc.\& Regional Dummies & Included & Included & 153 \\
No. of observations & 304 & 151 & -425.9 \\
Log Likelihood & -977.2 & -541.9 & $92.1 * * *$ \\
Wald Chi-squared & $507.4 * * *$ & $384.5 * * *$ &
\end{tabular}

Notes: $* p<0.1 ; * * p<0.05 ; * * * p<0.01$. Robust standard errors are in parenthesis. 
Table 8. OLS estimates. Dependent variable: geographical distance (in $\mathbf{k m}$ ) for university-business partnerships

\begin{tabular}{|c|c|c|c|c|c|c|}
\hline & \multicolumn{2}{|c|}{ Total sample } & \multicolumn{2}{|c|}{ Engineering-related } & \multicolumn{2}{|c|}{ Basic-science related } \\
\hline & (I) & (II) & (III) & (IV) & (V) & (VI) \\
\hline $\begin{array}{l}\text { Top ranked Dept. } \\
\text { (Medium \& Low ranked as ref.) }\end{array}$ & $\begin{array}{c}-0.115 * * \\
(0.053)\end{array}$ & --- & $\begin{array}{c}-0.113 * \\
(0.061)\end{array}$ & --- & $\begin{array}{c}-0.319 * * \\
(0.138)\end{array}$ & --- \\
\hline $\begin{array}{l}\text { Low ranked Dept. } \\
\text { (Top \& Medium ranked as ref.) }\end{array}$ & --- & $\begin{array}{c}0.151 * * * \\
(0.052)\end{array}$ & --- & $\begin{array}{l}0.215 * * * \\
(0.056)\end{array}$ & --- & $\begin{array}{l}-0.065 \\
(0.139)\end{array}$ \\
\hline Res. Intensive Univ. & $\begin{array}{c}-0.144 * * * \\
(0.046)\end{array}$ & $\begin{array}{c}-0.137 * * * \\
(0.046)\end{array}$ & $\begin{array}{l}-0.030 \\
(0.053)\end{array}$ & $\begin{array}{l}-0.019 \\
(0.050)\end{array}$ & $\begin{array}{c}-0.382 * * * \\
(0.103)\end{array}$ & $\begin{array}{c}-0.387 * * * \\
(0.110)\end{array}$ \\
\hline Ex-polytechnic Univ. & $\begin{array}{c}-0.256 * * * \\
(0.086)\end{array}$ & $\begin{array}{c}-0.327 * * * \\
(0.087)\end{array}$ & $\begin{array}{c}-0.249 * * \\
(0.094)\end{array}$ & $\begin{array}{c}-0.356 * * * \\
(0.096)\end{array}$ & $\begin{array}{c}0.097 \\
(0.223)\end{array}$ & $\begin{array}{l}-0.005 \\
(0.221)\end{array}$ \\
\hline Ind. Funding p.c. & $\begin{array}{l}-0.033 \\
(0.037)\end{array}$ & $\begin{array}{l}-0.015 \\
(0.037)\end{array}$ & $\begin{array}{l}0.008 \\
(0.044)\end{array}$ & $\begin{array}{c}0.027 \\
(0.043)\end{array}$ & $\begin{array}{c}-0.124 * \\
(0.067)\end{array}$ & $\begin{array}{c}-0.115 * \\
(0.068)\end{array}$ \\
\hline Gov. Funding p.c. & $\begin{array}{l}-0.021 \\
(0.051)\end{array}$ & $\begin{array}{l}-0.022 \\
(0.049)\end{array}$ & $\begin{array}{l}-0.095 \\
(0.058)\end{array}$ & $\begin{array}{l}-0.098 \\
(0.056)\end{array}$ & $\begin{array}{c}0.259 * * \\
(0.102)\end{array}$ & $\begin{array}{c}0.166 \\
(0.108)\end{array}$ \\
\hline Dept. Size & $\begin{array}{c}-0.102 * * * \\
(0.036)\end{array}$ & $\begin{array}{c}-0.108 * * * \\
(0.035)\end{array}$ & $\begin{array}{c}-0.092 * * \\
(0.039)\end{array}$ & $\begin{array}{c}-0.092 * * \\
(0.037)\end{array}$ & $\begin{array}{l}-0.185 \\
(0.125)\end{array}$ & $\begin{array}{c}-0.320 * * * \\
(0.113)\end{array}$ \\
\hline No. Univ. in the region & $\begin{array}{c}-0.095 * * * \\
(0.029)\end{array}$ & $\begin{array}{c}-0.097 * * * \\
(0.029)\end{array}$ & $\begin{array}{c}-0.079 * * \\
(0.033)\end{array}$ & $\begin{array}{c}-0.080 * * \\
(0.033)\end{array}$ & $\begin{array}{c}-0.135 * * \\
(0.054)\end{array}$ & $\begin{array}{c}-0.138 * * \\
(0.054)\end{array}$ \\
\hline No. Partnerships / firm & $\begin{array}{c}0.138 * * * \\
(0.017)\end{array}$ & $\begin{array}{c}0.139 * * * \\
(0.017)\end{array}$ & $\begin{array}{c}0.123 * * * \\
(0.019)\end{array}$ & $\begin{array}{c}0.125 * * * \\
(0.019)\end{array}$ & $\begin{array}{c}0.157 * * * \\
(0.038)\end{array}$ & $\begin{array}{c}0.155 * * * \\
(0.039)\end{array}$ \\
\hline Grant. Total value & $\begin{array}{c}0.029 \\
(0.021)\end{array}$ & $\begin{array}{c}0.028 \\
(0.021)\end{array}$ & $\begin{array}{c}0.027 \\
(0.026)\end{array}$ & $\begin{array}{c}0.027 \\
(0.026)\end{array}$ & $\begin{array}{c}0.025 \\
(0.039)\end{array}$ & $\begin{array}{c}0.016 \\
(0.039)\end{array}$ \\
\hline Intercept & $\begin{array}{c}5.816 * * * \\
(0.454)\end{array}$ & $\begin{array}{c}5.731 * * * \\
(0.450)\end{array}$ & $\begin{array}{c}5.721 * * * \\
(0.520)\end{array}$ & $\begin{array}{c}5.565 * * * \\
(0.511)\end{array}$ & $\begin{array}{c}5.487 * * * \\
(0.937)\end{array}$ & $\begin{array}{c}6.501 * * * \\
(0.931)\end{array}$ \\
\hline Ind./Dis./Reg. Dummies & Included & Included & Included & Included & Included & Included \\
\hline $\mathrm{N}^{\mathrm{o}}$. observations & 3765 & 3765 & 2819 & 2819 & 946 & 946 \\
\hline $\mathrm{F}$ & 7.02 & 7.13 & 5.17 & 5.50 & 5.13 & 4.96 \\
\hline Prob $>$ F & 0.000 & 0.000 & 0.000 & 0.000 & 0.000 & 0.000 \\
\hline R-squared & 0.069 & 0.070 & 0.056 & 0.59 & 0.151 & 0.146 \\
\hline Root MSE & 1.187 & 1.187 & 1.125 & 0.124 & 1.329 & 1.333 \\
\hline
\end{tabular}

Notes: $* p<0.1 ; * * p<0.05 ; * * * p<0.01$. Robust standard errors are in parenthesis. 


\section{Appendix}

Table 1A. Descriptive statistics $\left(1^{\text {st }}\right.$ part of the analysis)

\begin{tabular}{|c|c|c|c|c|c|c|c|c|c|c|c|}
\hline & Mean & $\begin{array}{c}\text { St. } \\
\text { Dev. }\end{array}$ & Min. & Max. & 1. & 2. & 3. & 4. & 5. & 6. & 7. \\
\hline 1. No. of Partnerships & 14.22 & 19.07 & 1 & 145 & 1.000 & & & & & & \\
\hline 2. Distance $(\mathrm{Km})$ & 354.04 & 410.60 & 1.81 & 2000 & -0.102 & 1.000 & & & & & \\
\hline 3. Score_rae & 5.38 & 1.11 & 2 & 7 & 0.324 & 0.021 & 1.000 & & & & \\
\hline 4. Tot. Inc. p.r. (£k) & 57.95 & 47.52 & 0.95 & 365.88 & 0.191 & -0.005 & 0.403 & 1.000 & & & \\
\hline 5. Dept_size & 29.40 & 22.69 & 2 & 167 & 0.431 & -0.043 & 0.498 & 0.287 & 1.000 & & \\
\hline 6. Res_int_univ & 0.37 & 0.48 & 0 & 1 & 0.211 & -0.048 & 0.522 & 0.268 & 0.359 & 1.000 & \\
\hline 7. Ex-Polytechnics & 0.18 & 0.38 & 0 & 1 & -0.197 & -0.035 & -0.547 & -0.266 & -0.354 & -0.353 & 1.000 \\
\hline
\end{tabular}

Note: Bi-variate correlations in bold indicate significance at $p<0.05$. The lowest tolerance for the independent variables here is $0.43(\mathrm{VIF}=2.3)$. Tolerance, which is the reciprocal of the Variance Inflation Factor (VIF), is a statistical tool used to detect collinearity amongst the independent variables. Tolerance is computed by regressing each variable on all other explanatory variables, calculating R2 and then subtracting that from 1. Low tolerances correspond to high multicollinearity, and are of concern when the tolerance is 0.2 or below (or VIF is 5 or higher).

Table 1B. Descriptive Statistics $\left(2^{\text {nd }}\right.$ part of the analysis)

\begin{tabular}{lccccc}
\hline Variables & Mean & St. Dev. & Min. & Max. & Obs. \\
\hline Distance $(\mathrm{km}) *$ & 166.45 & 134.98 & 0 & 840.87 & 4148 \\
Top rank & 0.30 & 0.46 & 0 & 1 & 4148 \\
Low rank & 0.29 & 0.46 & 0 & 1 & 4148 \\
Research. Intensive Univ. & 0.52 & 0.49 & 0 & 1 & 4148 \\
Ex-Polytechnic Univ. & 0.08 & 0.27 & 0 & 1 & 4148 \\
Industry fund. per year \& c. (£k)* & 12.51 & 8.89 & 0 & 53.11 & 4075 \\
Gov. funding per year \& c. (£k) * & 42.80 & 32.11 & 0.54 & 359.77 & 4075 \\
Dept. Size (n. active researchers) $*$ & 42.04 & 31.99 & 2 & 167 & 4075 \\
No. Univ. in the Region & 7.76 & 2.61 & 2 & 14 & 4148 \\
No. partnerships by firm * & 10.60 & 21.53 & 1 & 123 & 4148 \\
Volume grant for partnership (£)* & $323,520.4$ & $734,268.5$ & $2,211.5$ & $11605,619.8$ & 4146 \\
\hline
\end{tabular}

*Note: all these variables were logarithmically transformed in the regression analysis. These tables present the raw values for all variables (i.e. not logarithmically transformed values) 